of the radiologists, and that surgery will be less and leas enlisted in the future for its treatment. The Radium Institute results in this complaint are very encouraging.

\section{Tonsillar Anaemia.}

Considerable difference of opinion still exists as to the wisdom of completely extirpating the tonsils, some claiming that an anaemia results from the removal of these haemopoietic organs. There are therefore advocates of the slicing or guillotine operation as against the thorough enucleation. My own experience leads me to adopt the enucleation plan, as less liable to be followed by recurrence of the hypertrophy. Aside from the primary or recurrent haemorrhage at the time of operation, which may be copious and account for a temporary marked anaemia, I liave not seen a chronic anaemia result after enucleation that would deter me from ablating these small haemopoietic glands, which are so often removed with manifest advantage to the patient.

Haemolytic Jaundice.

This is a peculiar acholuric jaundice, which may be either congenital or acquired, and which may last for years; it is a slow blood disease, with marked anaemia from destruction of red blood cells. In this disease splenectomy has a high curative value, and may arrest the disease quite promptly and satisfactorily.

\section{Purpura Haemorrhagica.}

In this disease, hitherto regarded as purely medical, the intervention of surgery is justified, and may prove curative. The spleen is distinctly enlarged, and its removal by splenectomy has been followed by the happiest results. The exact nature of the disease is ill-understood, and why there should be a deficiency of the fibrin-forming elements is not explained. Though apparently not primarily a splenic disease, still the extirpation of the spleen is very useful. In some way it breaks a link in the vicious circle that underlies this malady. Hence a fair field for surgery in this blood disease may be predicted.

Skin Grafting.

Brief reference may be made to important discoveries of interest to practical surgeons in respect to skin grafting. It is desirable before taking grafts, even from a mother to her child, to determine whether the bloods of both harmonize or are homologous. When they do not correspond there may be failuro in grafting - a point of speciul importance when the larger flights in plastic surgery are attempted.

\section{Blood-letting.}

A word must be said about a practice against which the errors and abuses of former generations have created some prejudice. I refer to blood-letting, either local or general. It is more than possible that we abstain from this too often, and that we should reconsider its value. Anyone who has seen the relief afforded by general blood-letting in the congestion of the lungs in immersion cases, and its recent revival in pneumonia, in apoplexy with high temperature and flushed face, will be willing to admit its potency. Similarly, in chronic kidney inflammation, with uraemia imminent, and in polycythaemia vera, as I have already mentioned.

\section{Artificial Leucocytosis.}

The artificial production of leucocytosis has received some attention since Metchniloff's experiments showed that the resisting power of the peritoneum against the invasions of virulent organisms could be temporarily increased by injections of sterile broths or peptone solutions. This might be utilized in cases where the surgeon dreaded the onset of sepsis in abdominal operations. The same principle has recently been adrocated in the treatment of influenza by the injection into the blood of substances capable of producing a general leuco. cytosis-for example, nucleinic acid or sodium cinnamateand favourable results have been claimed for this practice.

In passing these various diseases in review it will be apparent that the account of them is necessarily incomplete and discursive. What will emerge, I think, is this, that surgeons in the future will have to be more thorough phisicicians and physiologists in order to guard themselves against rash or precipitate extirpations of organs which may be temporarily enlarged and apparently inconvenient burdens. These may not be the seat of the disease, though they may constitute its most conspicuous feature. The enlargement may actually be salutary-of the nature of a functional hypertrophy to protect the patient-as in polycythaemia.

On the other hand, the physicians shonld see to it that surgical aid should be sought as early as possible after a diagnosis has been made of one of these maladies in which splenic or glandular extirpation has proved of service. In a word, is it not clear that any sharp clearage between these sister sciences, to which a premature and exclusive specialisn is prone, is as unphilosophic as it is unscientific? We should, therefore, condemn an unnatural divorce of surgery and medicine, though both branches must gratefully recognize that only by specialized "team work" in many cases can the necessary diagnosis be laboriously built up.

\section{THE TREATMENT OF INSOMNIA.* \\ BY}

ROBERT DAWSON RUDOLF, M.D.,

PROFISSOR OF THERAPEUTICS IN THE UNIVERSITY OF TORONTO.

The treatment of cases of insomnia is a very large subject, and here only an outline can be given, founded on an attempt to classify the different forms of the affection under two great heads.

Physiologists cannot tell us exactly what sleep is, and it would serve no useful purpose to enunciate here the different theories-or shall I say hypotheses? - that have been advanced as to its nature. A common belief is that the lowering of blood pressure that undoubtedly occurs during sleep is the cause; but if this were so one should find intense drowsiness in cases of low blood pressure, but this is not usual. Sleeplessness is not a symptom of severe haemorrhage, and, on the other hand, I understand that in mania the blood pressure tends to be low. Again, chloralose is a good hypnotic, and yet it raises the blood pressure. A fall in blood pressure is a usual accompaniment, but probably not the cause of sleep.

Sleep and sleeplessness are associated with decrease or increase respectively in the activity of the cells of the central nervous system, and the cause of this decrease or increase is not always the same. Sleeplessness, indeed, is a symptom and not an entity. One might just as well speak of one kind of cough or one kind of pain as of one kind of insomnia. We see it occur in arterio-sclerosis when the arterial blocd pres. sure may be high, and again in anaemia when it is probably low. Usually a cup of coffee will lead to sleeplessness, but I have known people in whom it has the opposite effect. Evidently the essential cause of the symptom is not the same in the two classes.

Sleeplessness is perhaps the most distressing symptom to which human flesh is heir. Every practitioner knows how it wears out his patients and how a few hours of sleep may alter the whole aspect of a case. Sleep is more essential to life than food, in that an animal may go for weeks without eating, but let it be deprived of sleep for four or five days and life becomes impossible. A form of torture said to have been popular in old days was to deprive the victim of s'esp, and it must have ranked high as a producer of exquisito suffering, which was the object of the torment. Our patients sometimes undergo this torture, unless we lessen it by therapeutic means.

As sleep is so essential, it follows that absolute insomnia for any length of time is incompatible with life, and yet often one is told by healthy-looking individuals that they have not closed an eye for weeks. I saw an example of this only the other day. A short period of sleeplessness is, strange to say, productive of an increase in weight of the body, but if the insomnia be persistent a loss of weight ensues, and the degree of emaciation is often an index of some value in estimating the amount of insomnia.

A great many classifications have been made of the different forms of insomnia. Perhaps the one most quoted is that of Germain Sée, which is as tollows:
1. Dolorous.
2. Digestive.
3. Cardiac and dyspnoeal.
4. Cerebro-spinal and neurotic.
5. Psychic.
6. Insomnia due to physical fatiguo.
7. Genito-urinary.
8. Febrile and auto-toxic.
9. Toxic.

* Communicated to a meeting of the Ontario Neuro-Psychiatific 
These nine classes are nine pigeon-holes in which we may put most cases of insomnia, but beyond that they are not of much value, as they are not founded upon any fundamental basis of classitication.

Whatcver be the ultimate nature of sleep, it appears to me that it depends upon two essential factors, and an increase in eithei, and especially in both, of these will prevent its sccurrence. These two factors are :

1. The degree of irritability of the central nervous system.

2. The amount of afferent inpulses reaching the central nervous system.

Table of Causes of Inscminia.

I. Nervous system hypersensitive, owing to-

(a) Inheritance, bad habit, alteration in habits

(b) Fatigue or neuras! henia.

(c) Circulatory disturbances, especially arterio-sclerosis and aortic regurgitation.

(d) Exciting toxins produced in the alimentary tract or in the body tissues, or introduced from without.

II. Increase in afferent impulses, as from noise, light, heat, or cold, mental or physical discomfort or pain.

If the irritability of the nerve cells be not abnormal, and if no excessive storm of afferent impulses arrive, then at rhthymic intervals unconsciousness steals over the brain and the individual sleeps, and during that sleep many bicchemical changes talse place which eventually cause him to awaken with powers renewed for the carrying on of the functions of active life. But let the central nervous system be too irritable from any cause, then, although only the normal amount of afferent stimuli be arriving, these will prove sufficient to prevent sleep; and it is well to remember here that although we may check all evident afferent stimuli, such as light, noise, pain, and so on, during all of life there occurs a constant flow of afferent impulses; which do not normally reach to the level of our consciousness and yet must have a stimulating effect upon the central structures, especially when the excitability of these is raised from any cause. Un the other hand, if the degree of irritability of the central nervous system be normal, let the amount of afferent impulses be only sufficient and sleep will be impossible. The most healthy man will be lept awake by an aching tooth or by sufficiently worrying thoughts.

It is easy to put most cases of sleeplessness into one of these two classes, although often a cause may act in both, as when indigestion reflexly causes distress and also increases the irritability by the production of toxins. Looking at Sée's nine classes it is evident that dolorous, genito-urinary, and rsychic cases come into our second group, in that they act by increasing afferent impulses; while those cases labelled cardiac and dyspnoeal, cerebro-spinal and neurotic, fatigue, febrile and auto-tox:c, and toxic, act by increasing the irritability of the central cells and hence come in the first group; and lastly, the digestive (and possibly many of the cardiac and dyspnoeal) act in both ways, and hence belong to both classes.

It is manifest that in many patients we are dealing with several causes of sleeplessness, as when we meet with a clironic renal patient who has business worries and who has been imbibing in order to keep himself up to the mark. He has an increased irritability of the central nerve cells due to the toxaemias from the nephritis and the alcohol, and he also has the increase in afferent impulses from the worrying thoughts. An irritable nervous system is being overstimulated, and of course he cannot sleep.

As regards treatment, an appreciation of the above grouping of the different causes of sleeplessness makes the problem, to me at least, a little less complex.

Although we do not know the essential nature of sleep we do know a great deal about the factors that will favour its occurrence, and, on the other hand, those that act in the opposite direction. By encouraging the former and decreasing the latter as far as possible we can usually, more or less, restore the deranged function.

Speaking generally, in every case we should reduce the flow of afferent impulses to as few as we can, and hence the patient must be placed where light, noise, heat, and cold do not disturb him. Many a sufferer is kept awake by cold feet or other result of an unequalized circulation. Noise keeps most people awake, and yet monotonous noise (like that of the engines of a steamer) may have a soothing effect, and sleeping passengers are usually waliened if the ship stops. Monotonous sound, especially if pleasant and rhythmic,' is calming, and hence the value of music in helping the sleepless.
When the afferent impulses are of the nature of pain or discomfort, then we strive to remove the cause of them; but if this be impossible and the centres continue to be stormed by such, then nothing will make these less sensitive to them than opium or its derivatives. But opium is a very edged tool in insomnia, unless this be dependent upon some disturbing condition which is likely to be of short duration, and it has no place in the treatment of chronic insomnia.

If the environment is made conducive to sleep and yet this is wooed in vain, then the central nerve cells are too irritable, and the cause of this irritability must be sought for and if possible removed. Going through our list it is evident that this can often be done. We cannot influence inheritance, but can bad habits, such as the reading of exciting boolss or indulging in exciting thoughts at night.

When a person is too tired to sleep, a stimulant such as tea or coffee, or even a glass of toddy, may make all the difference. Circulatory disturbances may frequently be treated success. fully, as when we use digitalis in cases of auricular fibrillation, and the sleeplessness is thus etiologically treated. In less evident circulatory abnormalities hydropathy is of special value and should always be tried. If the feet are cold a hot bottle may help, or a hot, or even a cold, foot-bath followed by friction may be effectual. A complete warm bath is often valuable, and in very excited cases this may be continueã for hours and the patient thus soothed to sleep. I have seen this apparentiy save life in chorea. Or we may use the wet pack, in which the patient is enveloped in a wet sheet for half an hour and then rubbed dry with a rough towel. The water may be warm, tepid, or cold. Occasionally gentle massage is of value in inducing sleep.

All these physical methods probably act by influencing the circulation. In toxaemia from infections or metabolic changes treatment can often do much ; in that due to toxins introduced from without, especially the purin bodies, alcohol and tobacco, the remedy is in our hands.

But in many cases, after all possible afferent stimuli have been checked and all possible causes of irritability of tho central cells have been removed, still too much excitement remains, and then, and only then, is it our duty to try and directly lessen this excitement by medicinal means.

Hypnotics should be avoided as much as possible, espe. cially. in chronic cases of insomnia, and never used until every other method has been tried. The two bogies that haunt us here are (1) habit formation, and (2) gradual loss of effect, so that the dose of the drug must be constantly increased. But sometimes sleep-producing drugs are necessary, it being wise ": to do little wrong to do a great right."

Every practitioner has his favourites here, and I will not weary you with any discussion of hypnotics in general; but will merely say that they should be used as seldom as possible, and in as small doses as will act. They all bring about sleep by dulling the excitability of the nerve centres.

When a hypnotic appears to be required it is wise to begin with the mildest, and here one can put the bromides. 'They can be given either at bedtime in a single dose of from 30 to 60 grains, or in several doses during the day. It makes little difference what form of bromide is employed. Sometimes a combination of several is preferred.

Next in order may come chloralamide, now official in the B.P. as Chloral Formamidum, in doses of 20 to 30 grains, given in solution flavoured with liguorice. Then veronal (dose 5 to 10 grains), and the action of this drug can be enhanced by the addition of an equal amount of aspirin (say 5 grains of each). Then the sulphones, sulphonal and trional, in doses of 10 to 25 grains; and lastly, chloral hydrate, in doses of 10 to 20 grains, repeated. Chloral is rapidly eliminated, and it is better to give it in repeated doses than in one large one, for some people are very susceptible to it, and cases are on record where 30 grains have proved fatal. Often a combination of several hypnotics acts better than a large dose of one. In excited cases paraldehyde in doses of onc-halt to one drachm is valuable, or we can use hyoscine hypodermically, although occasionally this increases rather than decreases the excitement. An ordinary dose of it hypodermically is $1 / 150$ grain.

Opium should never be used in chronic insomnia, although, as already said, in acute disease, as pneumonia, it is often invaluable.

Some have used hypnotism in producing sleep, but if of it I have no personal experience, and in the $f \in w$ cases in which I have seen it tried I have not been much impressed with its value. 
Summary.

1. All cases of insomnia may be classificd as being produced cither by an increase in the excitability of the nerve centres, or from an increase in the afferent stimuli reaching those centres, or by both.

2. In every case the afferent stimuli should be reduced as much as possible, and to this end, after the environment has been made as appropriate as practicable, physical therapy, especially hydrotherapy, should be employed.

3. If the excitement of the cerebral centres remain too great, then this may have to be reduced by the employment of hypnotics, and here the mildest should first be used.

4. Opium and its derivatives should never be employed in the treatment of chronic insomnia, or in that dependent upon abnormal mental states.

\section{RICKETS : A THEORY OF THE METABOLIC DIS'TURBANCES AND OF 'I'T ASSO- CIATION WITH 'TEIANY.}

$\mathrm{BY}$

D. NOËL PATON, M.D., F.R.S.

(From the Institute of Physiology, University of Glasgow.)

\section{Introduction.}

ANY explanation of tho etiology and pathology of rickets must take cognizance of the fact that it is not merely a bone disease, but that the symptoms show that there is a profound and general disturbance of the metabolism. The sweating, the muscular wealness, and the close association with the spasmophilic condition all point in this direction. Miss Ferguson ${ }^{1}$ found that 43 per cent. of the markedly rachitic and 41 per cent. of the slightly rachitic children examined by her in Glasgow had, or had had, tetauy. The slight legenerative change in the muscles, first described by Bing in 1907 and again by $B a n u^{2}$ in 1921, with the altered chronaxie recorded by Bourguignon and Banu, ${ }^{3}$ and the clecrease in the creatin content found by Pearl Henderson, ${ }^{4}$ inclicate that muscle is implicated as well as bone.

Although the causal factors in the production of the disease are still quite obscure in spite of the immense amount of work which has been done upon the subject, the course of mstabolism is beginning to be somewhat better understood. Probably nothing has done more to delay progress than the general acceptance of the belief that a defective supply of caleium to the bones is the basal factor, and the failure to recognize that the decreascd ossification may be due to a limitation in the supply in proper form of some other clement in bone. While calcium constitutes some 50 por cent. of dr:ed dense bone, phosphoric acid $\left(\mathrm{P}_{2} \mathrm{O}_{5}\right)$ constitutes about 40 per cent.

\section{Phosphoric Acid as the Possible Limiting Factor in} Ossification in Rickets.

Recent work is pointing more and more to the primary incolvcment of phosphoius rather than calcium in the pervcrled metabolism of rickets.

Howlaud and Marriot's luave published a large series of observations on the calcium content of the serum of the blood in rashitic and non-rachitic children showing no marked decrease in the calcium, and more recently Howland and $K_{\text {ramer }}{ }^{6}$ give a parallel series showing a marked decrease in the inorganic phosphates. The analyses of Findlay, Noël Paton, and Sharpe ? laad shown no decrease in the calcium content of the whole blood of rachitic pups, and a scries of metabolic studies upon children led them to conclude that the evidence does not point to a primary implication of the metabolism of calcium. 'The recent work of $\mathrm{BcCollum}$ and others ${ }^{8}$ shows that a limitation of the phosphates of the food in proportion to the calcium, especially when accompanied by a limitation in the fat-soiuble A accessory factor, produces in rats a condition of the bones resembling that in rickets. Some unpublished metabolic studies by Telfer also afford an indication that in rickets there is a decrease in the proportion of the retention of phosplıorus to the retention of calcium, as had long ago been maintained by Schabad. ${ }^{9}$

'The evidence thus terds to indicate that failure in the supply of phosphoric acid, or its supply in unsuitable forms, may be the limiting factor in the ossification in rickets, and this suggests a possible disturbance in the metabolism which may explain not only the bone changes in rickets but also its association with tetany. This I propose to discuss.

It was formerly supposed that the inorganic matter of bone is composed of some 87 or 88 per cent. of calcium pliosphate, with some 10 or 11 per cent. of calcium carbonate, but it is now recognized that the calcic phosphate and carbonate pro. bably occur in a more complex combination, which Gassman 13 considers may be represented by the formula :

$$
\mathrm{Ca}\left[\left\{\begin{array}{lll}
\mathrm{O}^{-} & \mathrm{PO} 3 & \mathrm{Ca} \\
\mathrm{Ca} & \\
\mathrm{O}^{\prime} & \mathrm{PO} 3 & \mathrm{Ca}
\end{array}\right\}^{3}\right] \mathrm{CC}_{3}
$$

The Carriage of Calcium in the Blood.

The very generally accepted theory that the bone salts are carried in the blood in the form in which they are deposited seems to be based upon the older analysis of the relative amounts of calcium and of phosphoric acid in the blood. Since the transference must occul through the plasma, it is the proportion of the two constituents present in this which requires consideration.

The amount of $\mathrm{CaO}$ is about $14 \mathrm{mg}$. per $100 \mathrm{c.cm}$. plasma. The amount of inorganic $\mathrm{P}_{2} \mathrm{O}_{5}$ is about 7.2 (Bloor). Hence the amount of calcium is in excess of that which could be carried as $\mathrm{Ca}_{3}\left(\mathrm{PO}_{4}\right)_{2}$, even if none of the inorganic phosphoric acid were combined with sodium and other bases. It has long been found difficult to explain the solution of the calcium in the plasma if it is present as a phosphate, and Hofmeister ${ }^{11}$ speculates upon the way in which it is held. He considers that it is greater in amount than can exist in simple solution. He discusses the various possibilities, and comes to the conclusion that the colloidal condition of the blood plasma, with its high protein content, render's' possible the transport of phosphates, calcium soaps, and lipoids, themselves insoluble in water, in the form of colloidal suspension.

Wells ${ }^{12}$ lays stress on the probab!e action by $\mathrm{CO}_{2}$ in dissolving lime salts and retaining them in solution, and refer's to the work of Barillé, who concludes thiat calcium is carried in the blood in a definite compound, a "carbon-phosphate" of calcium,

\section{$\mathrm{P}_{2} \mathrm{O}_{8} \mathrm{Ca}_{2} \mathrm{~T}_{2}$ : $2 \mathrm{CO}_{2}\left(\mathrm{CO}_{3} \mathrm{H}_{2} \mathrm{Ca}_{2}\right.$}

which, on evaporation to dryness, yields about 77 per cent. of $\mathrm{CaHPO}_{4}$, and about 23 per cent. of $\mathrm{CaCO}_{3}$. In an alkaline medium $\mathrm{Ca}_{3} \mathrm{PO}_{4}$ is formed. Wells points out that 77 parts of the di.calcium phosphate would yield 87.7 parts of tri-calcium phosphate, which is the proportion in bone. Howland and Kramer elaborate this explanation, and point out that "a decrease of the phosphorus $\left(\mathrm{HPO}_{4}\right)$ ion would render more difficult the precipitation of tertiary calcium phosphate."

On the other hand, Rona and Takahashi ${ }^{13}$ found that some 20 to 30 per cent. of the calcium of the serum was not diffusible, and MacCallum, Limbert, and Vogol ${ }^{14}$ were unable to dialyse all the calcium out of the plasma. Cushny ${ }^{15}$ finds that while all the inorganic phosphoric acid may be filtered turough a collodion filter, at least one-third of the calcium is retained. Von Meysenburg, Pappenheimer, Zucher, and Murray ${ }^{16}$ found that 60 to 70 per cent. of the calcium of serum is diffusible. These facts strongly suggest that the calcium is not all combined with phosphoric acid as assuined by Hofmeister, but that it is in some other combination. Vines ${ }^{17}$ gives some evidence that part of the calcium of the blood exists in the ionized and part in the non-iovized condition.

The interesting observations of Paul and Sharpe ${ }^{18}$ on the transport of calcium in the blood of the crab, from the liver to the shell, in combination with lower fatty acids, suggests the possibility of its being linked in the blood of mammals to some other substance than phosphoric acid.

Again, the fact that the lime for the bones of the chick comes from the calcium carbonate of the shell of the egg; while the phosphorus for the phosphoric acid comes froin the lecithin of the yolk (Plimmer and Scott), ${ }^{19}$ suggests that a combination is not formed till the bone is reached. Haines 20 describes the abundance of phosphorized fats in the liver of the chick in the form of isotropic globules during the first two weeks, and finds that during the third week anisotropic globules of cliolesterol esters of fatty acids take their place. He suggests that a break-up of the lecithin complex and a recombination of the fatty acids occurs, and that the glycerophosphoric acid, or some other compound, passes on to take part in ossification, whilo cliolesterol takes the place of glycerol in ester combinations with the fatty acids.

Further, the fact that the subcutaneous or intraperitoneal injection us almost any soluble lime salt leads to patches of 